\title{
Plano de Ação da Equipe de Saúde para o Programa Zo’é
}

\author{
Plan of Action of the Health Team for the Zo'é Program
}

Eric Leonardo Jennings Simões ${ }^{1}$

Suely de Brito Pinto ${ }^{2}$

Sandra Ferrera Pena ${ }^{3}$

\begin{abstract}
Resumo:
A experiência da área da saúde junto a povos indígenas de recente contato tem mostrado que uma das maiores agressões a esses povos da floresta é a procura de assistência médica em centros urbanos. Quando isso ocorre, os indígenas passam a dividir com os brancos o mesmo espaço físico, recebendo as mesmas ações massificadas da área da saúde, sem que sejam levadas em consideração as particularidades étnicas e culturais de cada povo, de cada indivíduo. Neste artigo defendemos a necessidade de manutenção de estrutura física e humana na própria área indígena, de forma que continue permitido a assistência à saúde, em território Zo'é, mesmo que isso envolva a necessidade de procedimentos de média complexidade.
\end{abstract}

Palavras-chave: Saúde, Povos indígenas, Políticas de saúde indígena, Povo Zo’é

\begin{abstract}
:
The experience of the health area with indigenous peoples has shown that one of the greatest aggressions to them is the search for medical assistance in urban centers. When this occurs, indigenous people share the same physical space with whites and receive the same mass actions of the health area, without taking into account the ethnic and cultural particularities of each people, each individual. In this article, we defend the need to maintain physical and human structure in the indigenous area itself, which continues to be allowed health care in Zo'é territory, even if this involves the need for medium complexity procedures.
\end{abstract}

Keywords: Health care, Indigenous people, Health policies, Zo'é people

\section{Um pouco sobre os Zo'é}

O povo Zo'é foi o último grupo indígena falante de uma língua TupíGuaraní a ser contatado. O seu contato definitivo com não indígenas ocorreu na segunda metade da década de 1980, mas só na década de 1990 a Fundação

\footnotetext{
${ }^{1}$ Médico, DSEI GUATOK/SESAI.

${ }^{2}$ Técnica de Enfermagem, DSEI GUATOK/SESAI.

${ }^{3}$ Técnica de enfermagem, DSEI GUATOK/SESAI.
} 
Nacional do Índio assume o controle da situação e passa a garantir a proteção dos índios, inclusive contra investidas externas de contato, caracterizadas altamente prejudiciais aos Zo'é.

A Terra Indígena Zo'é, denominada atualmente Frente Etnoambiental Cuminapanema, foi homologada em 2009, com uma extensão de 668,5 mil hectares distribuídos em parte dos municípios de Óbidos, Oriximiná e Alenquer, na confluência do Rio Paru de Oeste ou Cuminã, com a margem esquerda do Rio Urucuriana, e afluentes da margem direita do Rio Cuminapanema (MEMORIAL DESCRITIVO DE DEMARCAÇÃO, 2009).

Os Zo'é somam atualmente 293 indivíduos (Dados da SESAI, julho de 2016), e sua população é predominantemente constituída de jovens. De acordo com Pena (2014), a população Zo'é, segundo critérios diageracionais, caracteriza-se como a seguir:

\begin{tabular}{|c|c|c|c|}
\hline \multirow{2}{*}{ Faixa etária } & \multicolumn{2}{|c|}{ Gênero } & \multirow{2}{*}{ Percentagem } \\
\cline { 2 - 3 } & Homem & Mulher & \\
\hline $0-4$ & 14 & 15 & $11 \%$ \\
\hline $5-9$ & 18 & 17 & $13 \%$ \\
\hline $10-14$ & 23 & 17 & $15 \%$ \\
\hline $15-19$ & 20 & 19 & $14 \%$ \\
\hline $20-24$ & 13 & 17 & $12 \%$ \\
\hline $25-29$ & 08 & 05 & $5 \%$ \\
\hline $30-34$ & 12 & 09 & $8 \%$ \\
\hline $35-39$ & 08 & 08 & $5 \%$ \\
\hline $40-44$ & 06 & 03 & $3 \%$ \\
\hline $45-49$ & 07 & 04 & $4 \%$ \\
\hline $50-54$ & 01 & 01 & $1 \%$ \\
\hline $55-59$ & 01 & 02 & $1 \%$ \\
\hline acima de 60 & 10 & 13 & $8 \%$ \\
\hline
\end{tabular}

Os Zo'é vivem da caça, da pesca, da coleta e de agricultura de coivara. Suas carnes de caça preferidas são o coatá (Ateles belzebuth), o guariba (Alouatta guariba) e o porcão (Tayassu pecari). Coletam mel, castanha, frutos de palmeiras, como patawa (Oenocarpus bacaba) e açaí (Euterpe oleracea), além de uma variedade significativa de outros frutos. Suas carnes são moqueadas e depois cozidas. Nas roças tradicionais dos Zo'é são plantados diferentes tipos de tubérculos - mandioca braba (Manihot esculenta), macaxeira, batata doce (Ipomoea batatas) e diferentes tipos de inhame (Dioscorea sp). Plantam também mamão, banana, algodão e urucum. Os Zo'e têm mais de uma roça que circunvizinham suas casas, construídas em locais distintos em função principalmente dos recursos naturais dos quais necessitam, como barro, flecha, 
peixes, caças e frutos.

Muito importante é o fato de que as diferentes casas servem também de refúgio de eventuais surtos epidêmicos (CABRAL e PINTO 2006).

Os Zo’é fazem uso de raízes e cascas de determinados paus para fins medicinais, assim como praticam a ingestão de bebidas fermentadas a base de batata doce, cará, banana, mandioca, açaí, bacaba, taperebá, entre outros, e do towari 'cigarro com folha de fumo e de outras ervas' para fins profiláticos e de purificação física e espiritual.

Na seção seguinte faremos um breve histórico do atendimento à saúde Zo’é, desde os primeiros contatos até a atualidade.

\section{Breve Histórico do atendimento à saúde Zo’é}

Em 1985, época das primeiras tentativas de contato dos Zo’é pelos missionários da Missão Novas Tribos do Brasil, inúmeras foram as mortes ocorridas decorrentes da vulnerabilidade desses índios face aos agentes etiológicos transportados para o contexto do contato por aqueles indivíduos estrangeiros. Os relatos dos Zo'é sobre essa época apontam um número surpreendente de óbitos relacionados a epidemias como a malária e a surtos viróticos gripais e diarreicos.

Na primeira década de atuação da FUNAI junto ao povo Zo’é, precisamente a partir de 1991, o Sertanista Sidney Possuelo fez as primeiras tentativas de implementação de uma política de recente contato que objetivava garantir a proteção física e psicológica dos Zo’é, a começar pela demarcação de sua terra e por um atendimento especial à saúde. De 1991 a 1997, enfermeiros da Funai e também servidores não especializados em saúde administraram procedimentos básicos de saúde junto aos Zo’é, como coleta de lâmina para pesquisa de plasmódio, diagnóstico e tratamento dos tipos de malária endêmicos -- Vivax e Falciparum --, tratamentos de viroses evidenciadas, tanto de gripes quando diarreicas, mas também aplicação de antídotos contra picadas de animais peçonhentos.

As doenças nesse período foram registradas com exatidão por funcionários da FUNAI, com atendimentos em decorrência de picadas de animais peçonhentos, fraturas por quedas e cortes acidentais com objetos cortantes. Nesse período não havia ainda a preocupação com uma vigilância epidemiológica, compreendendo estágios desde a notificação até a investigação.

Em 1997, a ONG Saúde e Alegria passa a assistir a saúde Zo’é, assegurando uma ação rotativa permanente de agentes de saúde em área. Mas será apenas em 1999 que a Fundação Nacional de Saúde (FUNASA) passa a se responsabilizar pela saúde Zo’é, em associação com o Sistema Único de Saúde (SUS), visando a estruturação e operacionalização da prevenção, assistência e promoção da saúde indígena. Em 2000, a Frente de Proteção Etnoambiental inicia um plano 
de ação interventiva para consolidar uma política de assistência à saúde Zo'é, comprometida com a integridade física, psicológica e cultural desse povo, assegurando desde procedimentos de cura à investigação epidemiológica, incluindo ações preventivas. Lobato $(2005$, p. 1.) relata:

"Deste investimento em saúde preventiva consta ampla cobertura vacinal periódica de toda a população, inclusive com vacinação contra haemophilus influenza (gripe), cujos antígenos virais são atualizados anualmente de acordo com a incidencia externa, as campanhas antimaláricas sucessivas, controlando um dos fatores de mortalidade que ao longo dos anos debilitava coletivamente a saúde do povo Zo'é."

Nesse momento da história das ações de saúde junto ao povo Zo'é, a nova política vai se consolidando orientada pela preocupação em "estruturar de modo exemplar os serviços de saúde para os Zo'é” (cf. Lobato, ibidem, p. 2). É nessa perspectiva que a então Coordenação Geral de Índios Isolados (CGIIRC/ FUNAI) investe na estrutura de atendimento da Frente, possibilitando pela primeira vez na história da saúde indígena brasileira que um grupo indígena se beneficiasse de tal forma que, quase a totalidade dos procedimentos de saúde passasse a ser realizada "prontamente" e "dentro do próprio território indígena".

Lobato (op. cit., p. 2) chama a atenção para os impactos negativos dos deslocamentos frequentes de indígenas na situação de contato para receberem atendimento de saúde fora de seu habitat:

"Os aspectos negativos de tais deslocamentos poderiam ser assim sintetizados:

- Alta demanda de tempo e de custos para deslocamento aéreo (o acesso da T.I. para o atendimento, em Santarém, significa cerca de 60 minutos para o avião chegar à área, mais 60 minutos para retornar a Santarém, afora o tempo inevitável de acomodações e trajetos internos).

- Os riscos de segurança inerentes ao trajeto aéreo e, posteriormente, rodoviário até a unidade de atendimento.

- Alto risco de contaminação hospitalar, inclusive a possibilidade do indivíduo indígena adquirir alguma patologia que pode ser catastrófica se carreada posteriormente para a terra indigena.

- Inadaptabilidade alimentar, medicamentosa, fisica, social e psicológica no sistema de internação hospitalar.

- Conflitos internos sociais, familiares, cosmológicos e psicológicos, 
diante de situações esdrúxulas de contato e conflito interétnico possiveis de ocorrências em ambientes urbanos e hospitalares.

- Conflitos internos relacionados à ausência de membros da comunidade, que em alguns casos imprimem problemas até mesmo de manutenção nutricional (como no caso da saída de homens caçadores - provedores alimentares importantes).

- Reforçar uma dependência tecnológica e cosmológica à cultura exógena, que aparenta dispor de todos os meios para promover a vida e deter a morte, o que sem dúvida é uma visão deturpada da medicina ocidental contemporânea, que perpassa na (in) compreensão indígena do "mundo dos brancos"."

Ciente de todos esses fatores que dificultam o pronto atendimento de saúde a populações que vivem em áreas de difícil acesso, e que põem em risco a vida dos índios, a CGIIRC dá início à estruturação de uma programa de saúde orientado pela necessidade de atendimento continuado e de pronto atendimento, em casos emergenciais, iniciando a prática de procedimentos cirúrgicos in loco, quando recomendado e quando possível.

No início do ano 2000, já se contava com a colaboração qualificada e voluntária de vários renomados profissionais de diferentes especialidades médicas, os quais não só prestavam abnegada assistência aos índios Zo'é, como buscavam a colaboração de instituições hospitalares, como o Hospital Círio Libanês, para a realização de cirurgias de alta complexidade, em área, com total sucesso, comprovando os benefícios trazidos pela prática do pronto atendimento in loco. Esse programa foi gerenciado, até 2002, pelo Instituto de Desenvolvimento das Atividades de Auto Sustentação das Populações Indígenas (INDASPI).

Em 2003, a Prefeitura do Município de Oriximiná passou a administrar os recursos financeiros e a manutenção da equipe de saúde atuante na área Zo'é. Em 2006, essa responsabilidade administrativa passa a ser da Prefeitura de Santarém, e só em 2010, com a criação da Secretaria Especial de Saúde Indígena (SESAI), do Ministério da Saúde, a responsabilidade total da saúde indígena sai da esfera municipal para a esfera federal, mas lançando mão da intermediação de ONGs, em virtude da terceirização de recursos humanos necessários à exequibilidade do novo programa de governo para as populações indígenas.

Adota-se como uma das estratégias de ação do novo programa a criação de equipes multidisciplinares de saúde indígena, constituídas de um médico, um odontólogo, dois enfermeiros e dois técnicos de enfermagem. Agora com a legitimação da presença de uma equipe especializada em área, o Programa de Saúde Zo'é, que já avançara metodologicamente e conceitualmente enquanto 
Programa voltado para as necessidades próprias de povos de situação de contato recente, só fortaleceu a sua atuação. Muito importante nesse contexto foi a observação da manutenção na nova equipe dos profissionais que já haviam adquirido experiência junto aos Zo'é ao longo de uma década, inclusive altamente respeitados pelo povo indígena e também conhecedor de hábitos culturais deste, e, ainda, importantemente, conhecedores da língua, requerimento básico e mandatório para uma atuação no âmbito da saúde, junto a povos monolíngues ou com conhecimento rudimentar do Português por apenas alguns indivíduos, como é o caso do povo Zo'é.

\section{Panorama atual do atendimento à saúde Zo'é}

Entende-se que cada ação, por mais simples que seja, tem como consequência uma experiência cultural diferente, trazendo consigo um conjunto de benefícios físicos, mas também podem acarretar malefícios, principalmente para a cultura. Cientes dessa possibilidade, todas as ações da área da saúde são discutidas internamente na perspectiva de que não causem danos ao equilíbrio dos Zo'é com o seu meio ambiente, evitando em sua realidade a ocorrência de mais doenças e sofrimentos, tantos físicos quanto psicológicos.

A experiência da área da saúde junto a povos indígenas tem mostrado que uma das maiores agressões a esses povos da floresta é a procura de assistência médica em centros urbanos. Quando isso ocorre, os indígenas passam a dividir com os brancos o mesmo espaço físico e recebendo as mesmas ações massificadas da área da saúde, sem levar em consideração as particularidades étnicas e culturais de cada povo, de cada indivíduo. Nesse sentido, nos últimos dez anos, a FUNAI tem se empenhado ao máximo em construir uma estrutura física e humana na própria área indígena, que tem permitido a assistência à saúde, em território Zo'é, mesmo que isso envolva a necessidade de procedimentos de média complexidade.

Em suma, o maior desafio e particularidade da assistência à saúde Zo'é é que se trata de uma estrutura permanente, definitiva, ao contrário de certas ações "em campanha" ou "expedições". Nos últimos cinco anos, tem-se construído uma estrutura permanente, onde o próprio povo Zoé possa se sentir dono dessa estrutura e com vínculos mais complexos e duradouros com aqueles que prestam assistência em área.

Logicamente, um dos principais obstáculos à construção de uma estrutura física e humana de assistência permanente em área indígena é o custo financeiro. Esta dificuldade tem sido parcialmente superada devido ao corpo de voluntariado médico e de outros profissionais de saúde que prestam seus serviços na área sem custo ao projeto. Atualmente, conta-se com cerca de dez profissionais médicos distribuídos segundo suas especialidades específicas, os quais, a qualquer momento, podem entrar em área e prestar seus serviços. 
Esse corpo de voluntariado especializado e gratuito é mantido graças a várias características culturais do povo Zo'é que juntas cativam os profissionais que visitam esse povo.

A principal delas é a amabilidade associada à afetividade cativante de praticamente todos que entram na área.

\section{Situação atual das ações e das demandas da área de saúde.}

Atualmente, as ações básicas de saúde são representadas pelo programa de vacinação do Ministério da Saúde, o qual é realizado em quatro ou cinco oportunidades ao ano e por ações de combate à malária, com inquéritos entomológicos, controle de vetores e diagnóstico, bem como tratamento dos casos.

A assistência médica é realizada por um médico coordenador da área e, quando necessário, há entrada de especialistas voluntários nas seguintes áreas: pediatra, cirurgião geral, cirurgião vascular, otorrino, oftalmologista, patologista, endocrinologista, gastroenterologista, radiologista, neurologista e infectologista.

Dois médicos radiologistas prestam serviços voluntários ao povo Zo'é, inclusive disponibilizando aparelho portátil de ultrassonografia, sendo realizados exames desta natureza em própria área, sem custo nenhum ao projeto.

Além de procedimentos cirúrgicos de baixa complexidade, outros procedimentos de média complexidade e alguns de alta complexidade têm sido realizados em área, como: correção cirúrgica de hérnia inguinal, endoscopia digestiva e cirurgia para catarata e colecistectomia por videolaparoscopia. Até o momento, não se registrou qualquer complicação médica grave destes procedimentos.

Por respeito à cultura, entende-se o respeito às crenças, restrições e normas sociais do povo. A exemplo, citamos o caso de um recém-nascido que adoeceu ao nascer, apresentando sintomas de febre alta, com quadro infeccioso. Por orientação médica, foi solicitado introdução de uma sonda nasogástrica para alimentação da criança. Entretanto, esse procedimento não foi realizado por impedimento da parte do avô da criança, o qual considerou o fato da fragilidade física do neto e de sua deficiência respiratória como impedimentos ao procedimento, pois a introdução da sonda poderia causar a morte da criança. Em vista da reação do avô, a equipe de saúde lançou mão de imagens de crianças com sonda já introduzida para explicar como seria o procedimento e o seu benefício à sobrevivência da criança. Mesmo assim, o avô não aceitou a realização do procedimento, tendo a equipe procurado solução alternativa adequada para suprir o uso do procedimento indicado pelo médico. Optou-se, então, pela alimentação paulatina do bebê por meio de uso de algodão, como mediador na ingestão de leite materno e soro oral, o que estabilizou o quadro, 
ao mesmo tempo respeitando princípios éticos e a cultura Zo’é.

Por respeito à cultura, entende-se, igualmente, que a saúde deve estimular as práticas de cura tradicionais, sempre que possível, ao invés de substituí-las por práticas alienígenas. Assim, quando um recém-nascido apresenta monilíase acompanhado de quadro de inanição, por exemplo, procura-se estimular a prática pelas próprias mães ou parentes próximos do uso de sumo da casca do pau de caju para limpeza da área bucal afetada, pois tradicionalmente é este o procedimento usado pelos Zo'é.

$\mathrm{O}$ atendimento à saúde Zo'é tem sido feito por equipe multidisciplinar permanente, com rotatividade de seus membros, respeitando o fato de que, em cada turno, se faça presente pelo menos um agente fluente na língua Zo'é e conhecedor tanto das famílias como de aspectos culturais do povo, principalmente de aspectos fundamentais de sua organização social.

Os Zo'é contam com total cobertura vacinal, desde o usufruto de campanhas nacionais de rotina, assim como pronto atendimento vacinal, independente de campanhas.

Quanto à infraestrutura local, os Zo’é são beneficiários de farmácia, constituída tanto de medicação básica, como de medicação especializada para as patologias diversificadas que historicamente os têm acometido.

A infraestrutura física de saúde na área Zo’é é constituída de uma farmácia-laboratório, um ambulatório preparado para a realização de cirurgias de média e alta complexidade, duas áreas cobertas, construídas em consonância com arquitetura análoga às casas locais, onde doentes ficam internados, e de um consultório odontológico para atendimento básico e preventivo.

Além desses edifícios há uma residência para alojamento da equipe multidisciplinar e para eventual hospedagem de médicos e outros agentes da saúde que entram na área para atendimento especializado aos Zo’é.

$\mathrm{O}$ atendimento à saúde Zo'é conta com transporte aéreo para traslado da equipe e para atendimentos emergenciais.

A equipe de saúde se mantém diariamente atualizada quanto às informações sobre as ocorrências, procedimentos e tratamentos de toda a população Zo'é, para o que fazem uso de um sistema de radio que interliga as aldeias Zo’é à base da Funai.

\section{Plano de Ação da Equipe de Saúde Multidisciplinar atuante junto aos Zo'é no âmbito do Programa Zo'é}

O modelo de assistência à saúde ao povo Zo'é norteia-se por três premissas fundamentais: respeito à cultura e às especificidades socioculturais e linguísticas do povo; assistência praticada em própria área indígena; e trabalho voluntariado junto povo. Esses princípios refletem a preocupação com uma 
assistência à saúde aliada ao fortalecimento da língua e da cultura do povo Zo’é:

- Respeito à cultura.

- Assistência à saúde com resolução em área de problemas de média e de alta complexidade.

- Trabalho voluntariado e parcerias.

Por respeito à cultura entende-se tanto a consideração dos tabus e conhecimento tradicional do povo Zo'é relativo à saúde em geral, quanto a adequação de procedimentos médicos, quando possível, às metodologias e aos elementos curativos tradicionais. Respeito à cultura significa também agir com ética profissional no trato com os pacientes e no convívio diário com a comunidade, minimizando interferências culturais inerentes à permanência dos agentes de saúde no seio da comunidade indígena.

Por assistência à saúde com resolução em área de problemas de média e de alta complexidade, entende-se que, para minimizar riscos de morbidade e mortalidade entre os Zo'é é necessário que se evite a retirada de indivíduos Zo'é da área indígena, visto que eles possuem baixa imunidade às patologias características dos meios externos ao seu habitat. Há de se considerar o fato de que indivíduos com histórico de recente contato como os Zo'é são altamente vulneráveis a doenças infecciosas e parasitárias, que podem rapidamente leválos a óbito. Nessa perspectiva, o traslado de indivíduos para hospitais em cidades deve ocorrer somente como retaguarda assistencial em casos de alta complexidade.

Por trabalho voluntariado, entende-se trabalho efetuado por meio de serviços prestados, convênios institucionais, mas ao mesmo tempo desenvolvido em uma perspectiva profissionalizante, ou seja, com vistas à preparação profissional de voluntários no âmbito do trabalho com a equipe multidisciplinar.

Para que um atendimento à saúde referenciado nessas premissas possa ser realizado, depende crucialmente de pessoal habilitado e de infraestrutura que garanta a exequibilidade do atendimento e de todos os procedimentos requeridos.

\section{A participação da equipe de saúde multidisciplinar no Programa Zo'e da Frente Etnoambiental Cuminapanema}

$\mathrm{O}$ atendimento à saúde Zo’é financiado pelo Ministério da Saúde tem atuado em parceria respeitosa com a Fundação Nacional do Índio, desde o ano 2000. Essa relação tem sido colaborativa e respeitosa em vários aspectos, desde a convivência pacífica, das equipes das duas instituições, em área, desde o respeito às decisões que cada uma das partes toma no âmbito de suas respectivas 
responsabilidades, evitando intromissões e discordâncias que interferiram no andamento das ações de responsabilidades de uma ou outra parte. A colaboração tem-se dado ainda com o compartilhamento dos benefícios de infraestrutura que viabilizam o trabalho em área de tão difícil acesso, como é o caso da terra Zo'é.

Além do serviço de saúde de alta qualidade prestado ao povo Zo'é pelo setor de saúde, a colaboração se consolida com o compartilhamento da infraestrutura de que dispõe a saúde, no suprimento de necessidades da Frente.

Assim, por exemplo, a Secretaria Especial de Saúde Indígena, por possuir agilidade na obtenção de transporte aéreo para traslado rotineiro da equipe, ou para traslado, em circunstâncias especiais, de doentes Zo'e para hospitais em Santarém ou em Belém, e ainda para transportar equipes de vacinação ou equipes médicas para procedimentos cirúrgicos in loco, tem disponibilizado espaços em seus voos para cobrir necessidades inerentes à equipe da FUNAI, o que tem sido também recíproco por parte da FUNAI.

A saúde tem também colaborado com o suprimento de combustível para produção de energia no posto da Frente e, em várias ocasiões, a equipe de saúde tem colaborado com a equipe da FUNAI quanto a resolução de problemas relativos a conflitos ocorridos entre os Zo'é, a maioria dos quais decorrentes dos contatos estimulados por agentes externos, como missionários e extrativistas clandestinos, que por razões diversas têm assediado e provocado distúrbios na tranquilidade social do povo Zo'é, inclusive expondo-os a situações de risco de saúde de difícil controle.

Na atualidade, com a criação do Programa Zo'é, há necessidade de se ampliara atuação da equipe de saúde, de forma que, além de suas responsabilidades próprias, colabore para que esse importante programa se sedimente com a participação de todas as instituições e indivíduos comprometidos com o bem estar físico, psíquico, social e cultural do povo Zo'é.

Propomos o seguinte plano de ação, em consonância com as metas da proposta de atuação da Saúde no Programa de Promoção Sociocultural do PZO'É, as quais têm em vista (a) ampliar o conhecimento dos Zo'é sobre as doenças e as práticas médicas dos "brancos", (b) promover um diálogo entre os conhecimentos tradicionais e os conhecimentos ocidentais, e (c) criar estratégias para que os Zo'é façam o nexo entre epidemias, saídas da Terra Indígena, invasões, saúde ambiental, entradas na TI de outros elementos, mesmo autorizados.

Para que a contribuição da equipe de saúde no processo educacional do Programa Zo'é se concretize, é mandatória que essa equipe realize os seguintes inventários:

- Registro em áudio e vídeo de interações verbais entre membros da equipe de saúde e os Zo'é, representativas de diversas situações de atendimento, incluindo procedimentos de médio e alto 
risco, estimulando manifestações dos Zo'é sobre as metodologias, técnicas e procedimentos utilizados.

- Registro escrito, em áudio e vídeo de metodologias, técnicas e medicamentos tradicionais da cultura Zo'é, obtidos através de entrevistas, sempre motivadas por situações de intervenções da equipe de saúde em processos de atendimento aos Zo’é.

- Levantamento e registro escrito, em áudio e vídeo do histórico da saúde Zo'e antes do contato e das práticas curativas utilizadas por eles.

- Levantamento e registro escrito, em áudio e vídeo, da prática dos regimes alimentares relacionados às várias fases que culminam em limites de estágios de existência dos Zo’é, e das várias doenças que os acometem.

- Levantamento e registro escrito, em áudio e vídeo, de como os Zo'é veem à medicina dos "brancos" empregada no atendimento que lhes é proporcionado pela equipe de saúde.

O material coletado em cada levantamento será analisado e sistematizado pela equipe e constituirá um importante banco de dados a serviço da saúde dos Zo'é, no desenvolvimento do programa educativo e para os Zo'é no futuro.

Este levantamento será realizado ao longo dos próximos três anos e ampliado na sequência, concebendo-se que parte importante desse levantamento versa sobre vasto conhecimento milenar de uma cultura em constante processo de mudança.

De posse do conhecimento dos temas inventariados, propomos as seguintes estratégias metodológicas para atingir as metas educativas propostas para o povo Zo'é:

- Reuniões mensais ou bimensais com os Zo'é na casa dos Mapas e nas aldeias, de três ou quatro dias, para discussão sobre origem das doenças, terapias, alimentação, e saúde ambiental.

- Reuniões semestrais de três ou quatro dias para discussão com os Zo'é sobre equivalências e diferenças entre as práticas de saúde efetuadas pela equipe de saúde e as práticas Zo’é.

- Reuniões com os Zo'é e com os funcionários e visitantes, principalmente em ocasiões de grandes reuniões - festas, campanhas de vacinação, entre outros -para tratar sobre o lixo nas aldeias e as consequências para a saúde e meio ambiente. 
Sobre a capacitação de jovens indígenas para o trabalho sanitário e epidemiológico, consideramos que, conhecendo e respeitando a cultura Zo'é, procurar-se-á identificar os indivíduos que poderão receber ensinamentos que os capacitem a atuar no trabalho sanitário e epidemiológico, podendo esses indivíduos ser os que culturalmente atuam como agentes curadores no seio das famílias Zo'é. Esse treinamento deverá ser adaptado ao ritmo de aprendizado/ensinamento Zo'é e deve ser realizado preferencialmente durante os atendimentos e procedimentos.

\section{Considerações finais}

Os Zo'é deverão ser envolvidos como principais agentes e pesquisadores nos levantamentos sobre temas relacionados à saúde do povo. Lançaremos mão também de projeções de filmes e de slides em Power Point, seguidas de discussão, como uma estratégia educativa de tópicos relativos à saúde Zo'é.

Ressaltamos que, como meta adicional a alcançar no âmbito do programa, é fundamental preparar a equipe de saúde para a pesquisa e para a alimentação do banco de dados relativo à saúde Zo'é, compreendendo aqui, os saberes nativos e os saberes externos.

Pretendemos publicar os principais resultados da pesquisa e do trabalho, em geral, de forma que o banco de dados da saúde e as publicações realizadas contribuam enquanto referência para outros programas voltados para outros povos que, como os Zo'é, merecem atenção especial das políticas públicas de saúde.

Finalmente, para que a participação da equipe de saúde no projeto seja viabilizada, será necessário o comprometimento da Secretaria Especial de Saúde Indígena, em providenciar as condições necessárias para a participação efetiva de seus quadros no programa em tela.

\section{Referências}

CABRAL, Ana S. A C. e Brito, Suely P. 2006. Relatório sobre saúde Zo’é (MS).

DADOS POPULACIONAIS ZO’É. DSEI/SESAI, 2016.

Lobato, João. Relatório da Frente de Proteção Etnoambiental Cuminapanema, apresentado à CERGIIC/FUNAI. 2005.

MEMORIAL DESCRITIVO DE DEMARCAÇÃO. FUNAI. 2009.

Pena, Sandra Ferreira. Perfil epidemiológico do povo Zo'é. Trabalho de Conclusão de Curso. Instituto Esperança de Ensino superior. 2014.

Recebido em julho de 2016

Aceito em setembro de 2016 